\title{
Mapa de visibilidad y posicionamiento en buscadores de los principales grupos mediáticos españoles
}

\section{Map of the visibility and search engine positioning of the main Spanish media groups}

\author{
Carlos Lopezosa; Lluís Codina; Guillermo López-García; Juan-María Corbella- \\ Cordomi
}

Cómo citar este artículo:

Lopezosa, Carlos; Codina, Lluís; López-García, Guillermo; Corbella-Cordomi, Juan-María (2020). “Mapa de visibilidad y posicionamiento en buscadores de los principales grupos mediáticos españoles". El profesional de la información, v. 29, n. 2, e290203.

https://doi.org/10.3145/epi.2020.mar.03

Artículo recibido el 04-10-2019

Aceptación definitiva: 13-01-2020

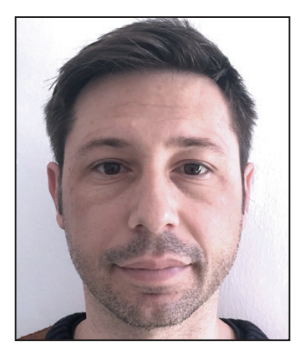

Carlos Lopezosa $\bowtie$

https://orcid.org/0000-0001-8619-2194

Universidad Pompeu Fabra

Roc Boronat, 138.

08018 Barcelona, España

carlos.lopezosa@upf.edu

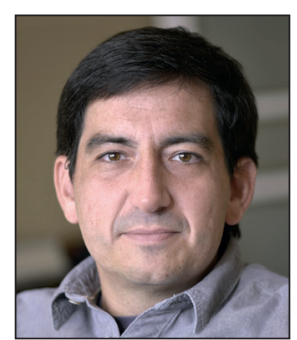
Guillermo López-García
https://orcid.org/0000-0002-5701-2024
Universidad de Valencia, Fac. de Filología Departamento de Teoría de los Lenguajes y Ciencias de la Comunicación Avda. Blasco Ibáñez, 32. 46010 Valencia, España guillermo.lopez@uv.es

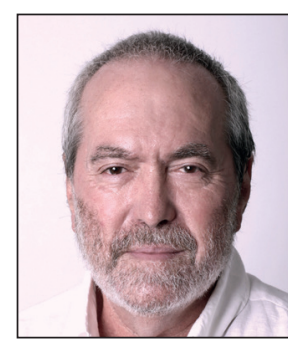

Lluís Codina

https://orcid.org/0000-0001-7020-1631

Universidad Pompeu Fabra

Roc Boronat, 138.

08018 Barcelona, España

Iluis.codina@upf.edu

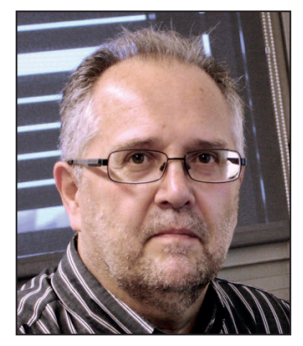

Juan-María Corbella-Cordomi https://orcid.org/0000-0003-1994-5875

Universidad Pompeu Fabra

Roc Boronat, 138.

08018 Barcelona, España

joan.corbella@upf.edu

\section{Resumen}

Este trabajo analiza la visibilidad y posicionamiento en buscadores de los sitios web de los principales grupos de comunicación españoles. Se compara su visibilidad web y su presencia en los resultados de búsqueda de Google a través de programas de análisis SEO y una metodología propia que se ha denominado Índice de Visibilidad Agregada. Se ha realizado un análisis comparativo de los grupos Atresmedia, COPE, Godó, Hearst Magazines, Henneo, Imagina Media Audiovisual, Intereconomía Corporación, Joly, Mediaset España Comunicación, Planeta, Prensa Ibérica, Prisa, Unidad Editorial, Vocento y Zeta. Se ha podido establecer que Unidad Editorial es el grupo con mayor tráfico web proveniente de búsquedas en Google, Prisa es el que tiene mayor número de enlaces externos apuntando a sus páginas web y Vocento el que tiene mayor número de palabras clave posicionadas en los buscadores.

\section{Palabras clave}

Grupos de comunicación; Grupos mediáticos; Empresas de medios; Medios de comunicación; Medios digitales; Visibilidad web; SEO; Posicionamiento en buscadores; Google; España.

\section{Financiación}

Este trabajo forma parte del proyecto "Narración interactiva y visibilidad digital en el documental interactivo y periodismo estructurado", RTI2018-095714-B-C21, Feder y Ministerio de Ciencia, Innovación y Universidades de España. 


\begin{abstract}
The visibility and the search engine positioning of the main Spanish communication groups' websites are analyzed. We compare their web visibility to their presence on Google's search results using SEO analysis tools and a methodology called Aggregated Visibility Index, developed by our investigation team. A comparative analysis of the groups Atresmedia, COPE, Godó, Hearst Magazines, Henneo, Imagina Media Audiovisual, Intereconomía Corporación, Joly, Mediaset España Comunicación, Planeta, Prensa Ibérica, Prisa, Unidad Editorial, Vocento and Zeta has been done. We conclude that Unidad Editorial is the group with the highest web traffic from Google searches, Prisa is the one with the highest number of external links pointing to its web pages, and Vocento is the group with the highest number of keywords positioned on search engines.
\end{abstract}

\title{
Keywords
}

Communication groups; Media groups; Media companies; Media ownership; Mass media; Digital media; Web visibility; SEO; Search engine positioning; Google; Spain.

\section{Introducción}

Ante la necesidad de difundir mensajes e informaciones a las audiencias a nivel global, los grupos mediáticos tienen que optimizar su visibilidad digital. Gracias a sus propias plataformas multimedia consiguen ocupar los primeros resultados en buscadores como Google o Bing, entre otros.

Las plataformas digitales en general, y entre ellas de modo destacado los buscadores, han modificado la manera en la que se accede y se consumen las noticias en internet (Iglesias-García; Codina, 2016) ya que gran parte de los usuarios tienden a mantenerse informados con consultas en Google (Giomelakis; Veglis, 2015; 2016; Iglesias-García; Codina, 2016; Arias-Robles, 2016). Una parte importante de usuarios no entra directamente a los webs de los medios de comunicación para informarse, bien sea porque lo hacen a través de los buscadores, como se ha señalado, o bien por la recomendación de contenidos vía redes sociales (López-García, 2015; 2017).

Por otra parte, el aumento del número de webs productoras de noticias ha provocado no sólo una mayor competencia (Rodríguez-Fernández; Sánchez-Amboage; Toural-Bran, 2018), sino además una gran dependencia de los medios de comunicación online con los buscadores y sus servicios. Sin ir más lejos, el tráfico directo de lectores que proporciona Google desde Estados Unidos y Europa puede alcanzar en algunos casos hasta el 80\% (Smyrnaios; Rebillard, 2009; Smyrnaios; Sire, 2014; Smyrnaios, 2015).

Dado este ecosistema informativo, el objetivo principal de este trabajo consiste en caracterizar la composición de los sitios web pertenecientes a los grupos mediáticos más representativos de España, con el fin de determinar su encaje en el ecosistema de la Web, su grado de visibilidad y con ello conocer su posicionamiento en buscadores. La selección de los grupos viene referenciada en Digimedios.es e Ymedia.es. Concretamente se estudian los grupos Atresmedia, COPE, Godó, Hearst Magazines, Henneo, Imagina Media Audiovisual, Intereconomía Corporación, Joly, Mediaset España Comunicación, Planeta, Prensa Ibérica, Prisa, Unidad Editorial, Vocento y Zeta.

A partir de este objetivo principal, los objetivos concretos de este trabajo son los siguientes:

1) Identificar los sitios web de cada uno de los grupos mediáticos considerados.

2) Determinar su visibilidad web en los resultados de búsqueda de Google utilizando indicadores significativos de posicionamiento web.

3) Elaborar un mapa de la visibilidad y posicionamiento en buscadores de los principales grupos mediáticos españoles utilizando los datos obtenidos en 1) y 2).

Dada la importancia y el impacto social de los grupos mediáticos y su necesidad estratégica con respecto a los motores de búsqueda, consideramos imprescindible conocer cómo son sus redes digitales y cómo aparecen éstas en los resultados de búsqueda.

\section{Marco teórico}

Si bien es cierto que los datos de las audiencias online están copados por unos pocos grupos de comunicación -principalmente por los medios de mayor tamaño y concentración de ingresos (Almiron, 2009)-, la mayoría de los grupos nacionales están aprovechando su potencial digital para hacer más visible su contenido informativo y aumentar su credibilidad (Humprecht; Esser, 2018).

En este contexto surgen nuevos retos para los grupos de comunicación, que pasan principalmente por:

- transmitir contenidos a las audiencias donde quiera que éstas se encuentren (Medina et al., 2017),

- enviar mensajes a nivel global que representen de manera coherente todo el conglomerado de entes vinculados a cada grupo de comunicación (Labio-Bernal; Nogales-Bocio, 2010; Reig, 2011),

- representar los intereses financieros de cada medio (Noam, 2017).

Uno de los indicadores más importantes para conocer la importancia dentro del sector de las webs de los medios de co- 
municación es reconocer su grado de posicionamiento en Google (Costa-Sánchez; Guarinos-Galán, 2018), ya que, como se ha explicado, con ello se obtiene más tráfico web, o lo que es lo mismo, más lectores.

Para obtener mayor visibilidad web, los medios de comunicación cuentan con un conjunto de técnicas o buenas prácticas (Google, 2019) conocidas como estrategias de search engine optimization (en adelante, SEO). Se trata de un proceso de optimización que ayuda a los motores de búsqueda a entender mejor un contenido, lo que redunda en una mejor posición de ese contenido en su índice de resultados.

Existen diferentes técnicas de SEO en cibermedios, descritas por los principales investigadores de este campo y que hacen referencia a los elementos más destacados sobre SEO on page, SEO off page y SEO técnico (Dick, 2011; Giomelakis; Veglis, 2015; 2016; Gonzalo-Penela, 2015). Como estrategias de posicionamiento en buscadores se aconseja usar la doble titulación (Asser, 2012) que tiene como objetivo:

- proporcionar el mejor titular para el lector;

- ofrecer el mejor titular para que los buscadores sean capaces de entender e indexar la noticia en sus resultados de manera eficaz; además, dicho titular debe incluir palabras clave para que los motores de búsqueda traten esas palabras como las más importantes (García-Orosa; López-García, 2014).

Las estrategias SEO deben encajar siempre con los valores periodísticos y con la calidad de las noticias (Charlton, 2016; Wordtracker, 2018; Wilson, 2016; Patel, 2019). Por ese motivo se aconseja el uso de estrategias SEO en tres esferas (Smyrnaios; Sire, 2014):

- los hechos noticiosos;

- la noticia en sí misma;

- la práctica periodística.

Asimismo, se recomienda una optimización SEO de noticias basadas en el libro de estilo de cada medio de comunicación (Codina et al., 2016).

Por último, a nivel técnico se recomienda el uso constante de herramientas de auditoría SEO dentro de una redacción periodística para analizar su posicionamiento en buscadores y encontrar debilidades o fortalezas y tomar medidas de mejora (García-Carretero et al., 2016; Lopezosa; Codina; Pérez-Montoro, 2019) y utilizar las páginas móviles aceleradas (AMP) como elemento diferenciador para que las noticias en cibermedios se posicionen. Entendemos como AMP la tecnología creada por Google que tiene como objetivo agilizar el peso de una web y, por tanto, hacer que un cibermedio se cargue a mayor velocidad.

En definitiva, el SEO en cibermedios trata de aplicar procesos de trabajo de optimización en buscadores que equilibren la calidad de las noticias y de la información con las mejores estrategias SEO (Codina et al., 2016).

\section{Metodología}

Para llevar a cabo esta investigación se ha elaborado un estudio de caso bajo la forma de los análisis comparativos (Eisenhardt, 1989; Coller, 2005; Yin, 2014). Para la construcción del caso (Coller, 2005), y para determinar las unidades que formaron parte del mismo, se procedió en primer lugar al estudio de la red de sitios de cada grupo de comunicación considerado, para lo cual tomamos como puntos de referencia o bien las páginas de créditos o bien las listas de enlaces corporativos en la navegación al pie de cada grupo.

Tabla 1. Grupos mediáticos analizados y enlace donde se ha localizado su red de sitios web

\begin{tabular}{|c|c|c|}
\hline ID & Grupo mediático & URL de identificación de la red de sitios web del grupo \\
\hline 1 & Atresmedia & https://www.atresmedia.com \\
\hline 2 & COPE & https://www.cope.es \\
\hline 3 & Godó & http://www.grupogodo.com \\
\hline 4 & Hearst Magazines & http://www.hearst.es/quienes-somos \\
\hline 5 & Henneo & https://www.henneo.com \\
\hline 6 & Imagina Media Audiovisual & Información corporativa en la web https://imagina.tv \\
\hline 7 & Intereconomía Corporación & https://www.grupointereconomia.com \\
\hline 8 & Joly & https://www.grupojoly.com/areas-de-negocio \\
\hline 9 & Mediaset España Comunicación & https://www.mediaset.es \\
\hline 10 & Planeta & https://www.planeta.es/es/medios-y-entretenimiento-audiovisual \\
\hline 11 & Prensa lbérica & https://www.prensaiberica.es \\
\hline 12 & Prisa & https://www.prisa.com/es \\
\hline 13 & Unidad Editorial & http://www.unidadeditorial.es \\
\hline 14 & Vocento & https://www.vocento.com \\
\hline 15 & Zeta & http://www.grupozeta.es \\
\hline
\end{tabular}


La selección de estos 15 grupos mediáticos está basada en su importancia intrínseca en el panorama comunicativo español, así como por su presencia histórico/tradicional en el mismo.

Ahora bien, para interpretar la lista de la tabla 1, hay que hacer algunas observaciones en relación con su composición. En primer lugar, si bien es cierto que el grupo Planeta posee (al 50\% con De Agostini) el 41,70\% de las acciones de Atresmedia, se ha tomado la decisión de mantenerlos como grupos separados, debido a la personalidad específica de Atresmedia. Motivos adicionales para ello son que Planeta no tiene la mayoría absoluta del capital y que al estudiarlos por separado se facilita la comparación directa entre Mediaset y Atresmedia, los dos grandes grupos rivales de la comunicación audiovisual en España.

Hay que señalar además que, aunque existe un proceso de compra de Zeta por parte de Prensa Ibérica, éste está todavía pendiente de autorización por la autoridad de la competencia en abril de 2019 (momento en el que se realiza este estudio), por lo que se ha considerado oportuno mantenerlos por separado, al no haberse hecho efectiva aún dicha compra.

La ventaja de mantener los datos de los grupos mencionados por separado es que, en escenarios donde pueda tener sentido para el lector o el investigador interesado, se pueden agregar los datos, mientras que fusionarlos ahora nos privaría de elementos de comparación.

En segundo lugar, y una vez identificada la red de sitios web de los grupos mediáticos seleccionados se ha llevado a cabo la toma de datos del 16 al 20 de diciembre del 2018. Esto ha consistido en aplicar los indicadores que proporciona el programa de análisis SEO SEMrush a todos los dominios centrales (página de inicio) de los sitios web de cada grupo. Los indicadores utilizados se muestran en la tabla 2.

Tabla 2. Indicadores utilizados para el análisis de los grupos mediáticos con SEMrush

\begin{tabular}{|c|c|c|}
\hline ID & Indicador & Descripción \\
\hline 1 & Número de webs por grupo mediático & $\begin{array}{l}\text { Ranking del número de webs con las que cuenta cada grupo mediático. A mayor número de } \\
\text { webs mayor puntuación y viceversa. }\end{array}$ \\
\hline 2 & Tráfico por búsqueda orgánica & $\begin{array}{l}\text { Cantidad mensual del tráfico web obtenido del sitio analizado. Se calcula según el número } \\
\text { de palabras clave posicionadas entre los } 100 \text { primeros resultados de búsqueda en Google y la } \\
\text { cantidad de búsquedas mensuales de cada una de estas palabras clave. Este indicador esti- } \\
\text { ma el tráfico de una web en base a su posicionamiento en Google y, por tanto, a su visibilidad } \\
\text { en los resultados de búsqueda. }\end{array}$ \\
\hline 3 & Enlaces de entrada o backlinks & $\begin{array}{l}\text { Número de enlaces externos que recibe el sitio web analizado. A mayor número de enlaces } \\
\text { se obtiene una mayor autoridad web y por tanto mayor tráfico. Por un lado, porque los usua- } \\
\text { rios pueden acceder a la web a través de los enlaces de terceros. Y, por otro, porque a mayor } \\
\text { autoridad web mayores posibilidades de ocupar lugares preferentes en Google. Por lo tanto, } \\
\text { este indicador señala, de manera significativa, la influencia del sitio web analizado. }\end{array}$ \\
\hline 4 & Número de dominios de referencia & $\begin{array}{l}\text { Cantidad de dominios de referencia (sitios webs distintos) que enlazan a la web analizada. } \\
\text { Un mismo dominio puede enlazar a la web en muchas ocasiones, por lo que tal web puede } \\
\text { recibir muchos enlaces de pocos sitios web o viceversa. A mayor número de dominios que } \\
\text { enlacen una web mayor influencia tendrá. En cambio, pocos dominios y muchos enlaces, } \\
\text { provocará poca influencia. Este indicador complementa los dos anteriores, ya que no sólo } \\
\text { modifica el punto de vista del análisis, sino que enriquece la información sobre el sitio web } \\
\text { analizado. }\end{array}$ \\
\hline 5 & Palabras clave & $\begin{array}{l}\text { Número de palabras clave por las que un sitio web aparece en el índice de los buscadores. } \\
\text { Se cuantifican todas las palabras clave por las que una web aparece entre los } 100 \text { primeros } \\
\text { resultados de Google. A mayor cantidad de palabras clave mayor visibilidad potencial posee } \\
\text { la web analizada. Una web puede obtener mucha visibilidad con un pequeño número de } \\
\text { palabras clave, o poca visibilidad para muchas palabras clave, ya que depende de la cantidad } \\
\text { de veces que los usuarios utilizan esas palabras para realizar sus consultas. Por lo que las } \\
\text { palabras clave populares tendrán un volumen de búsqueda mensual alto y viceversa. }\end{array}$ \\
\hline
\end{tabular}

En tercer lugar, aplicamos el Índice Agregado de Visibilidad (en adelante IAV). Este índice ya se ha aplicado en otros trabajos de investigación sobre visibilidad web (Lopezosa; Codina; Rovira, 2019) para poder sintetizar resultados. En este caso, aunque los indicadores utilizados son diferentes a los ya aplicados, su conceptualización sigue las mismas directrices ya que incluye:

- selección de indicadores de visibilidad con utilización de software de análisis SEO;

- asignación de valores binarios o escala simple de puntuación;

- aplicación de los análisis a la muestra seleccionada;

- tabulación de puntuaciones según la muestra analizada;

- sumatorio de indicadores y presentación en tablas de síntesis.

La función del IAV es mostrar los puntos fuertes y débiles de cada uno de los grupos de comunicación y dar una idea global de su calidad de visibilidad web en comparación con los demás grupos mediáticos analizados. El valor final depende de los grupos analizados y sólo tiene sentido en un estudio comparativo con estos medios.

La aplicación del IAV se basa en este contexto en la combinación de 5 indicadores cuyos valores fluctúan entre 1 y 14 
(estos números se basan en el número de grupos mediáticos analizados). El índice se obtiene dividiendo la puntuación total conseguida por cada medio por el máximo que es posible conseguir, que es igual a 70 . Un medio que sume los 70 puntos (los 5 indicadores puntuados con el máximo de 14) tendría un IAV igual 1, mientras que un medio que obtenga la mínima puntuación (1) en cada indicador tendría un IAV igual a 5/70 =0,07. Cuanto mayor sea la puntuación más visibilidad tendrá el grupo mediático analizado.

Para calcular el IAV se han seleccionado los indicadores más significativos y se ha considerado que cada uno de ellos tiene la misma importancia. Seguidamente pasamos a explicar el método utilizado para cada indicador (I).

- I1. Número de webs por grupo mediático: ranking del número de webs con las que cuenta cada grupo. Cuanto mayor es el número de webs, mayor puntuación y viceversa.

- 12. Tráfico por búsquedas: cuanto mayor tráfico web tenga un grupo mediático procedente de búsquedas orgánicas (no pagadas), mayor puntuación obtendrá del índice IAV y viceversa.

- 13. Enlaces de entrada: el grupo mediático que obtenga un mayor número de enlaces de entrada obtendrán una mayor puntuación del índice IAV y viceversa.

- 14. Dominios de referencia: el grupo con mayor número de dominios que le enlazan tendrá una mayor puntuación del IAV (15 puntos) y el que sea enlazado por menor número de dominios obtendrá una menor puntuación (1 punto).

- 15. Palabras clave en top 100: a mayor número total de palabras clave situadas entre las 100 primeras posiciones de los resultados de Google por cada grupo mediático mayor puntuación del IAV y viceversa.

\section{Resultados}

En este apartado presentamos en primer lugar un diagrama de redes de sitios web de cada uno de los grupos analizados. En segundo lugar, recogemos los aspectos más destacados sobre la visibilidad web de nuestro estudio de caso y en tercer lugar aplicaremos los resultados al IAV.

Debemos señalar que la fecha (entre el 16 y el 20 de diciembre del 2018) se indica por motivos de trazabilidad y transparencia, pero queremos recordar que, al no corresponder a un estudio de contenidos, los datos que se obtienen no son representativos de la fecha concreta, sino que aportan resultados acumulados de cada grupo, con lo cual la información obtenida es de tipo estructural.

En definitiva, la estructura que seguiremos para presentar cada caso será la siguiente:

- Diagrama de la red del grupo;

- Tabla de datos de influencia digital;

- Interpretación.

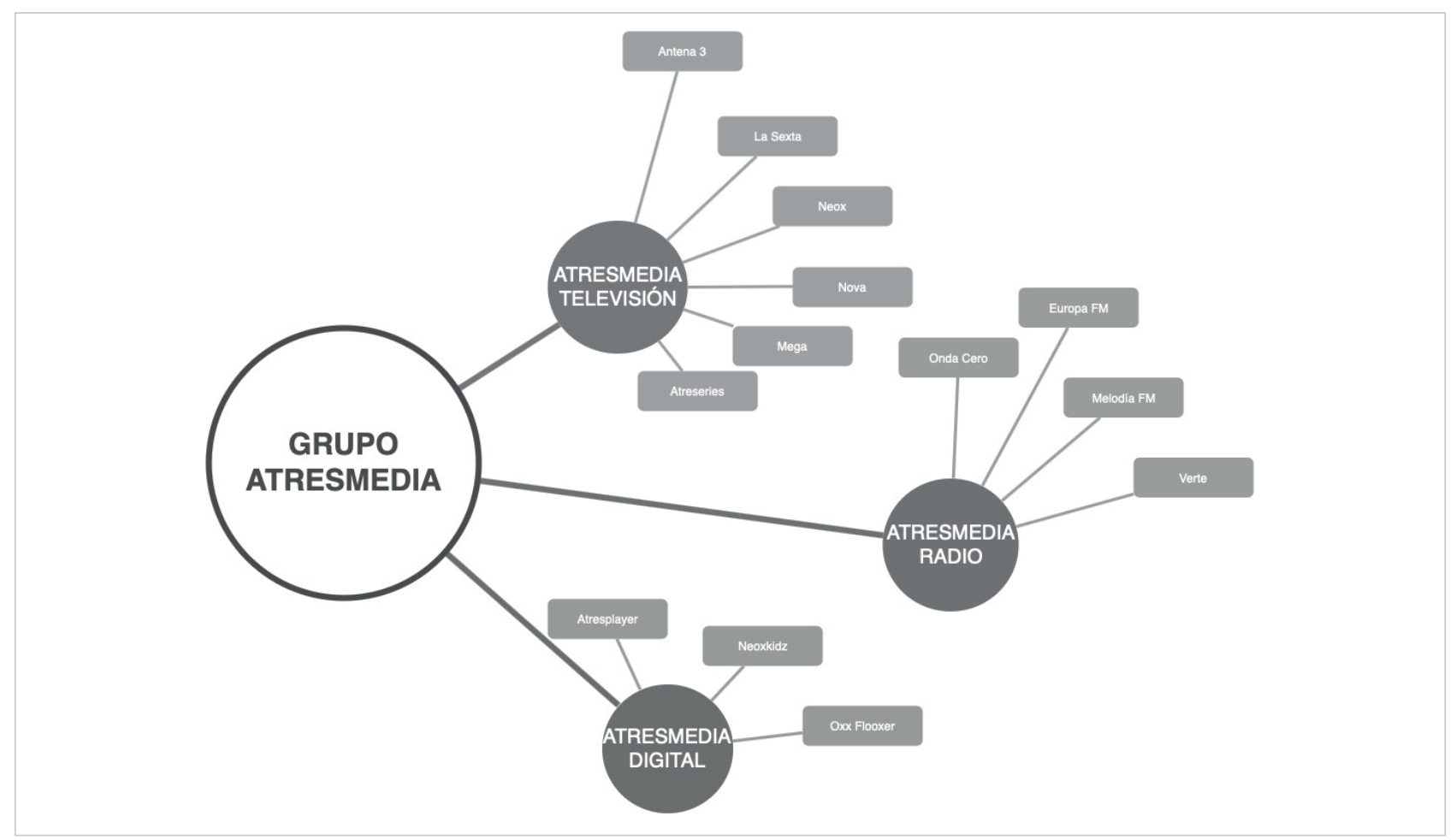

Imagen 1. Red de sitios web del Grupo Atresmedia.

Fuente: elaborado con datos de la web oficial del Grupo Atresmedia. 


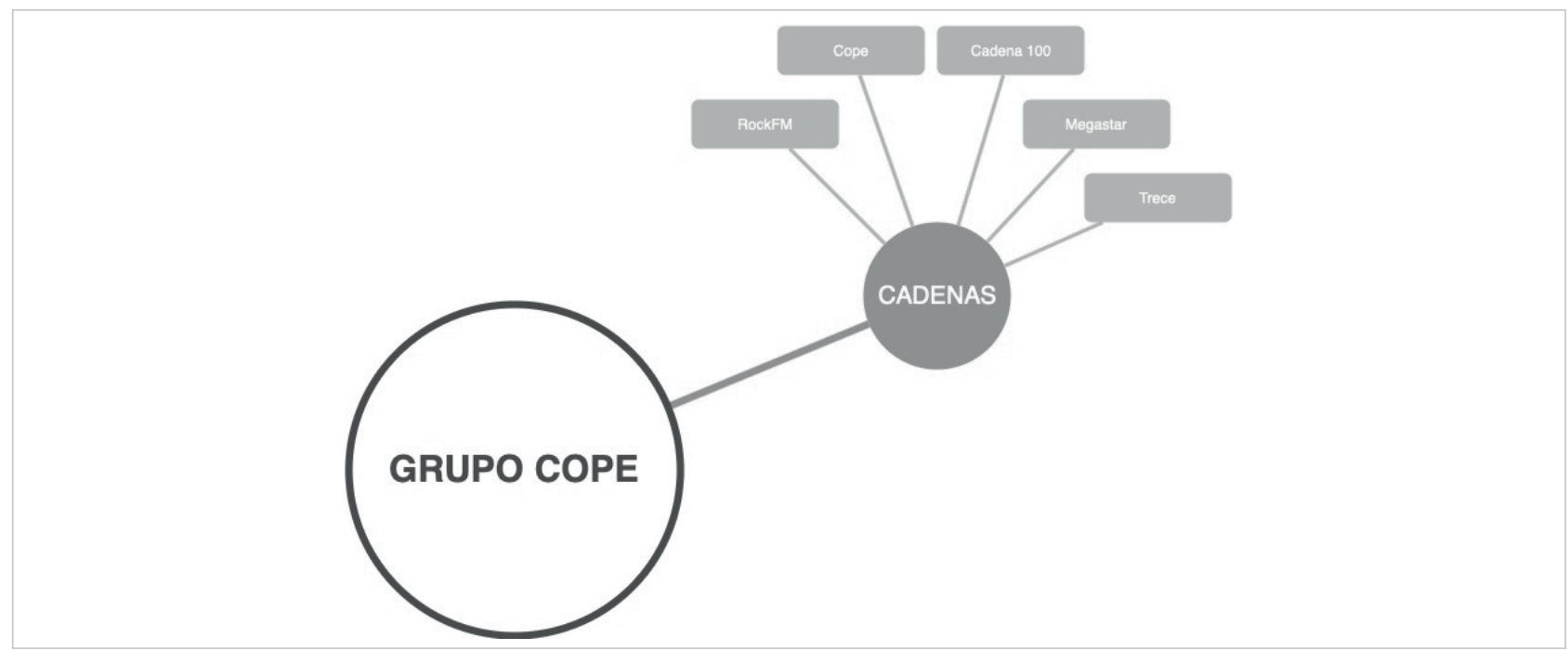

Imagen 2. Red de sitios web del Grupo COPE.

Fuente: elaborado con datos obtenidos de la web oficial del Grupo COPE

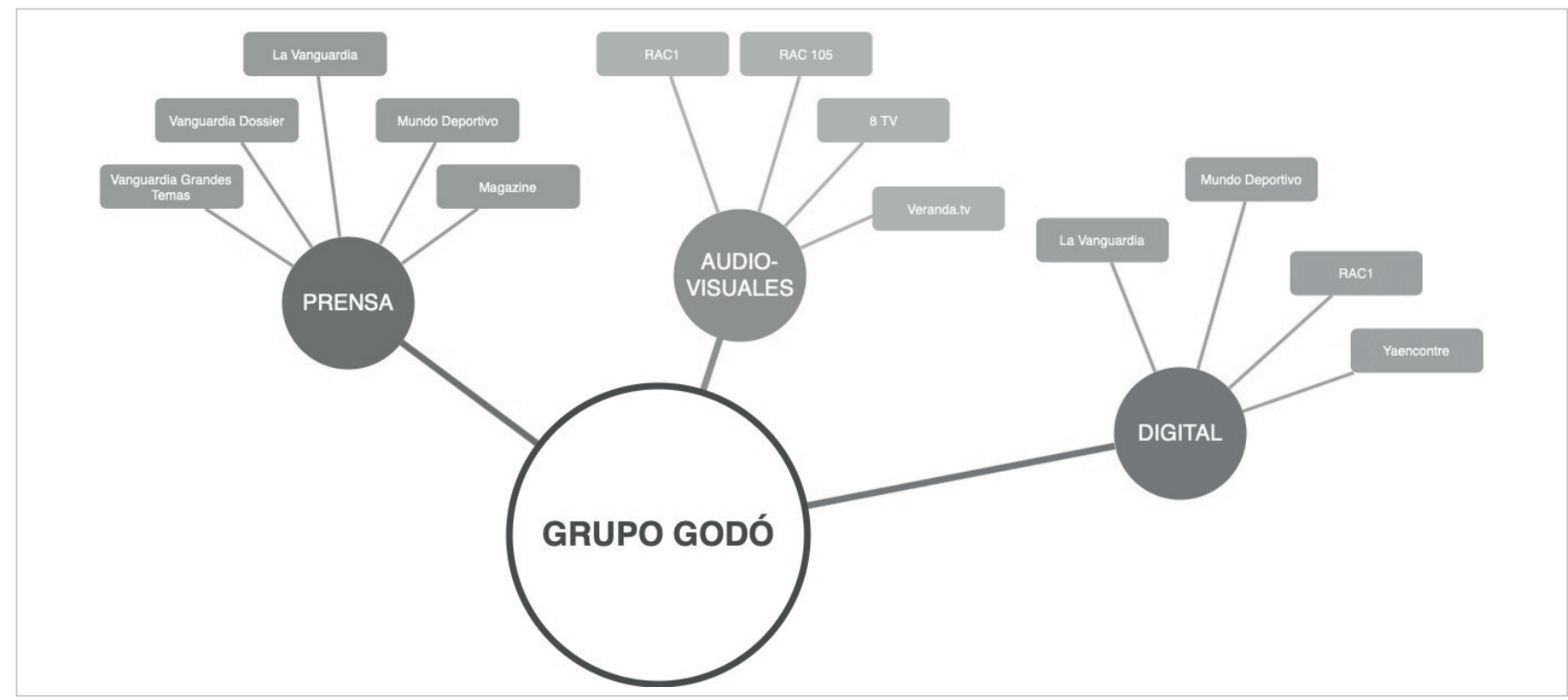

Imagen 3. Red de sitios web del Grupo Godó.

Fuente: elaborado con datos de la web oficial del Grupo Godó

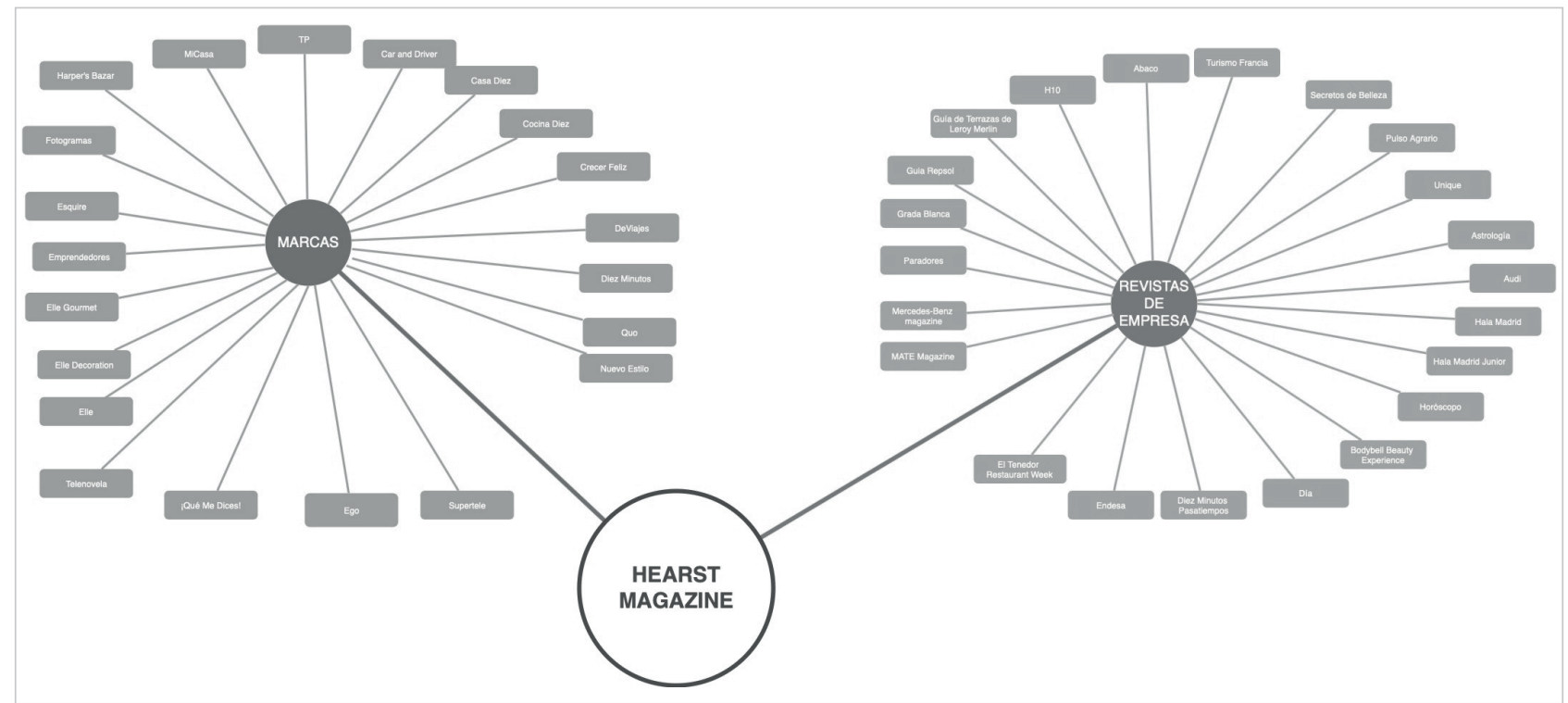

Imagen 4. Red de sitios web del Grupo Hearst Magazine.

Fuente: elaborado con datos de la web oficial del Grupo Hearst Magazine 


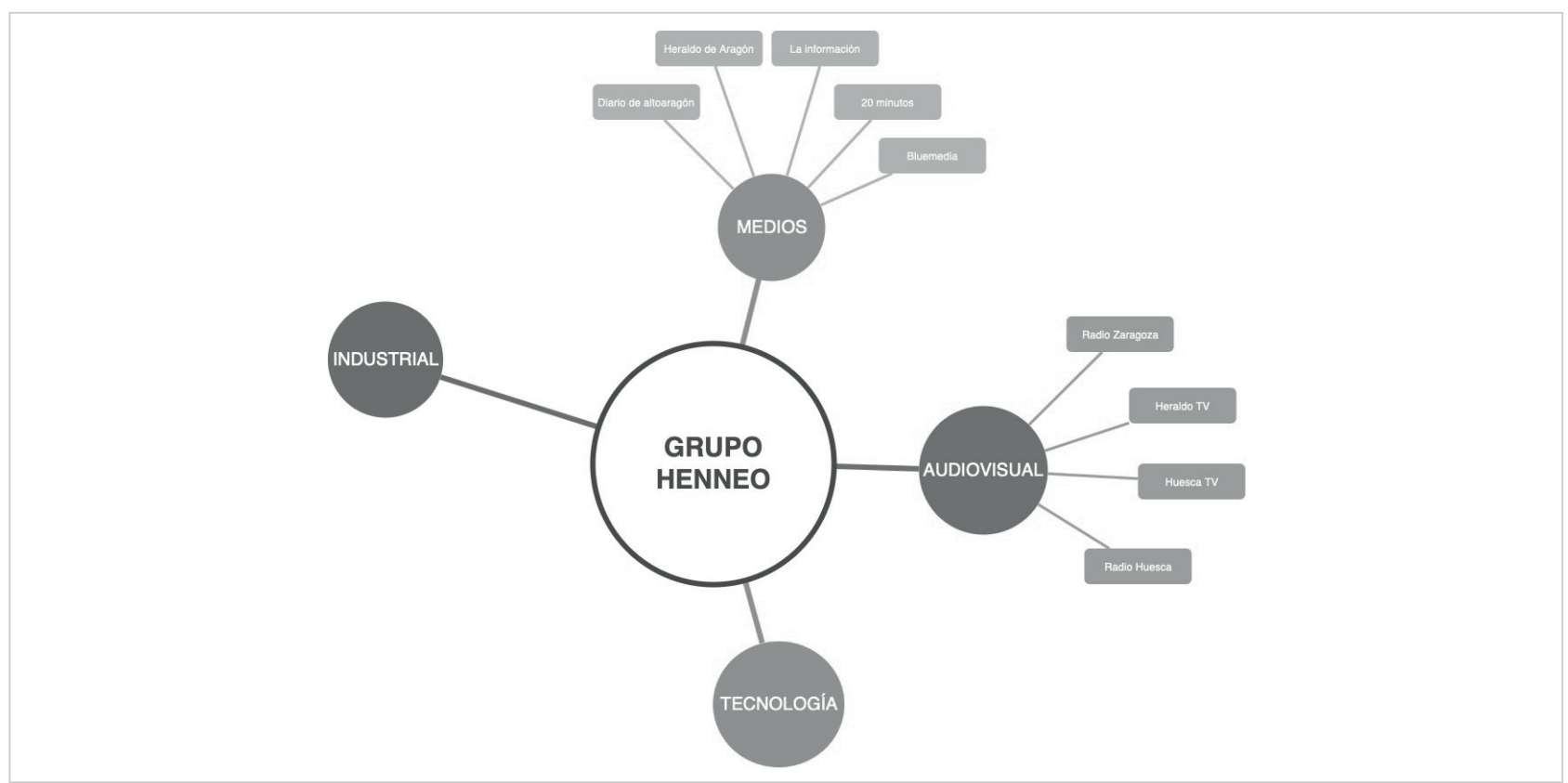

Imagen 5. Red de sitios web del Grupo Henneo.

Fuente: elaborado con datos de la web oficial del Grupo Henneo

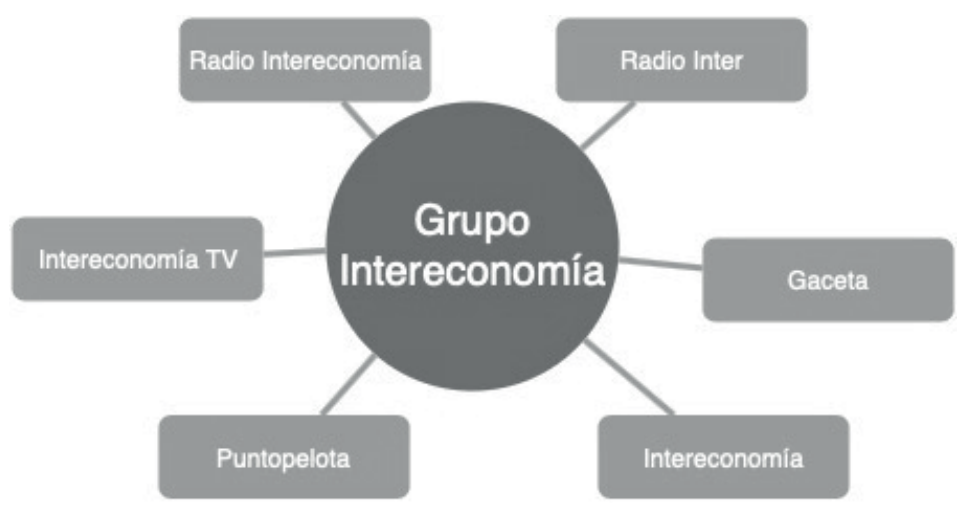

Imagen 6. Red de sitios web del Grupo Intereconomía.

Fuente: elaborado con datos de la web oficial del Grupo Intereconomía

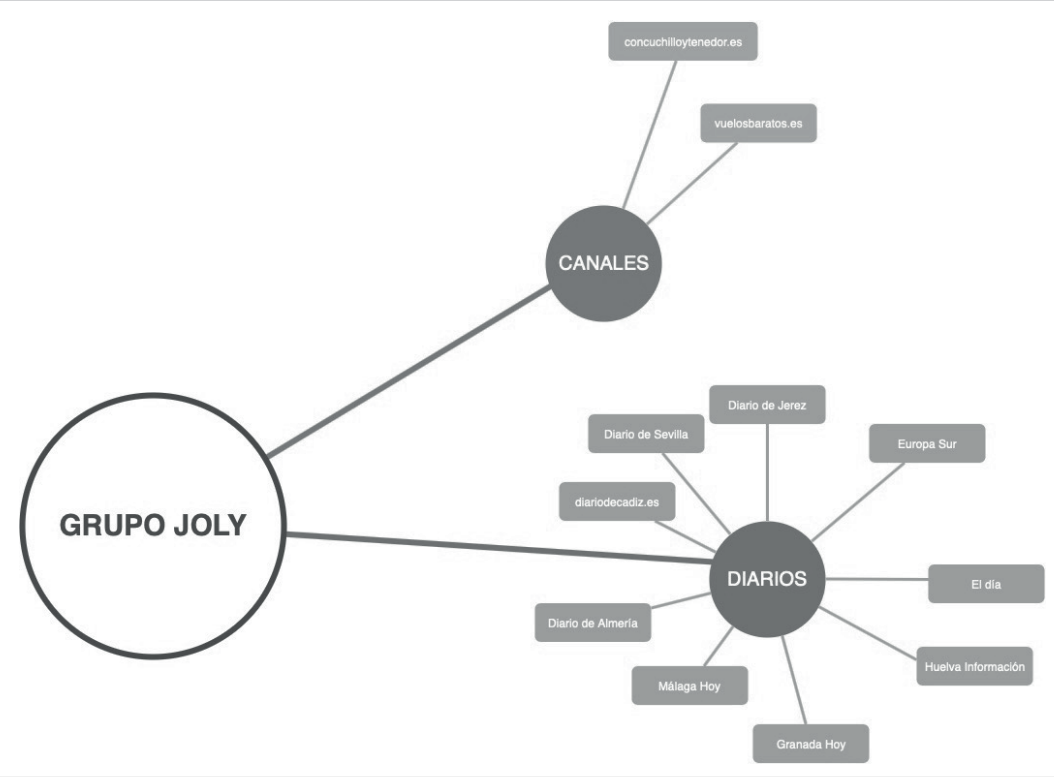

Imagen 7. Red de sitios web del Grupo Joly.

Fuente: elaborado con datos de la web oficial del Grupo Joly 


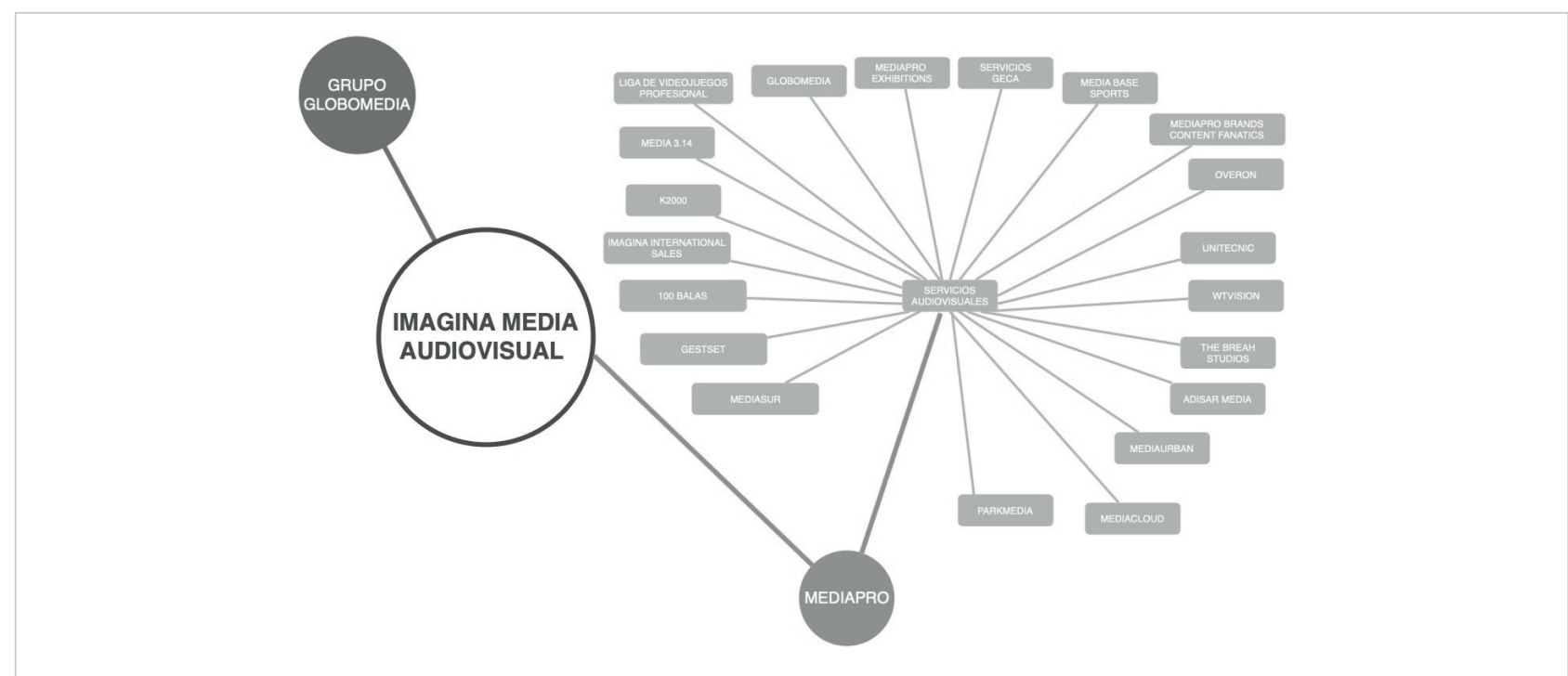

Imagen 8. Red de sitios web del Grupo Imagina Media Audiovisual.

Fuente: elaborado con datos de la web oficial de Imagina Media Audiovisual

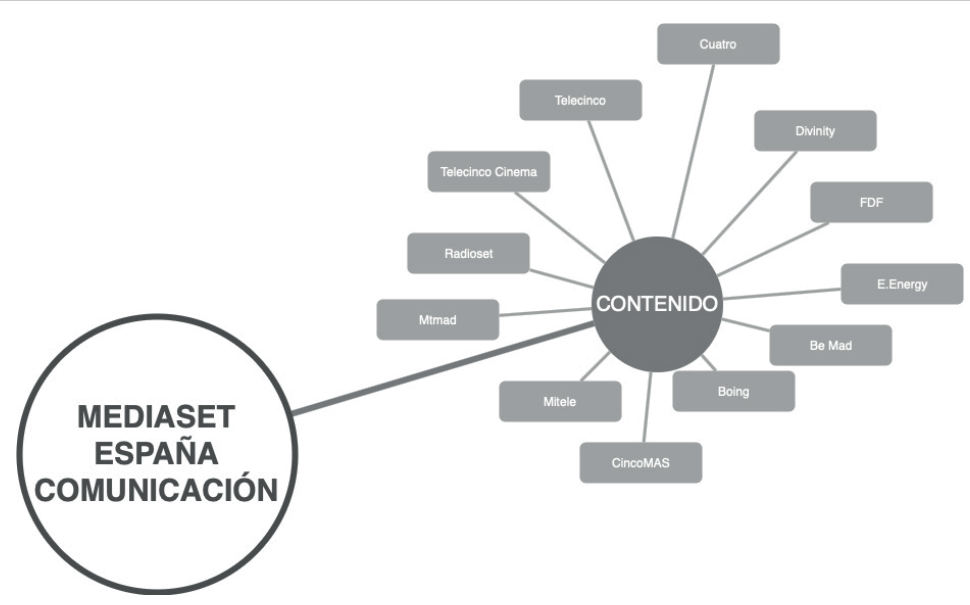

Imagen 9. Red de sitios web del Grupo Mediaset España Comunicación.

Fuente: elaborado con datos de la web oficial del Grupo Mediaset España Comunicación

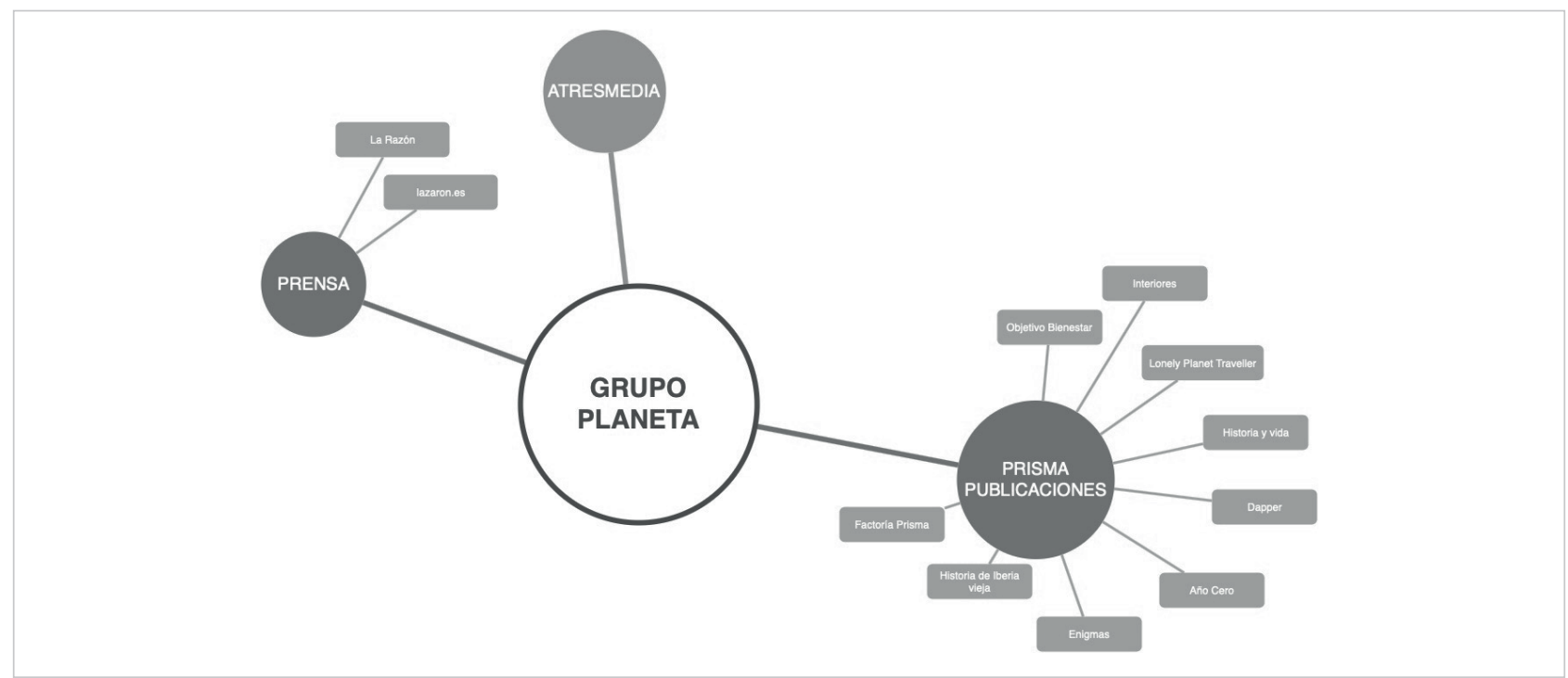

Imagen 10. Red de sitios web del Grupo Planeta.

Fuente: elaborado con datos de la web oficial del Grupo Planeta. 


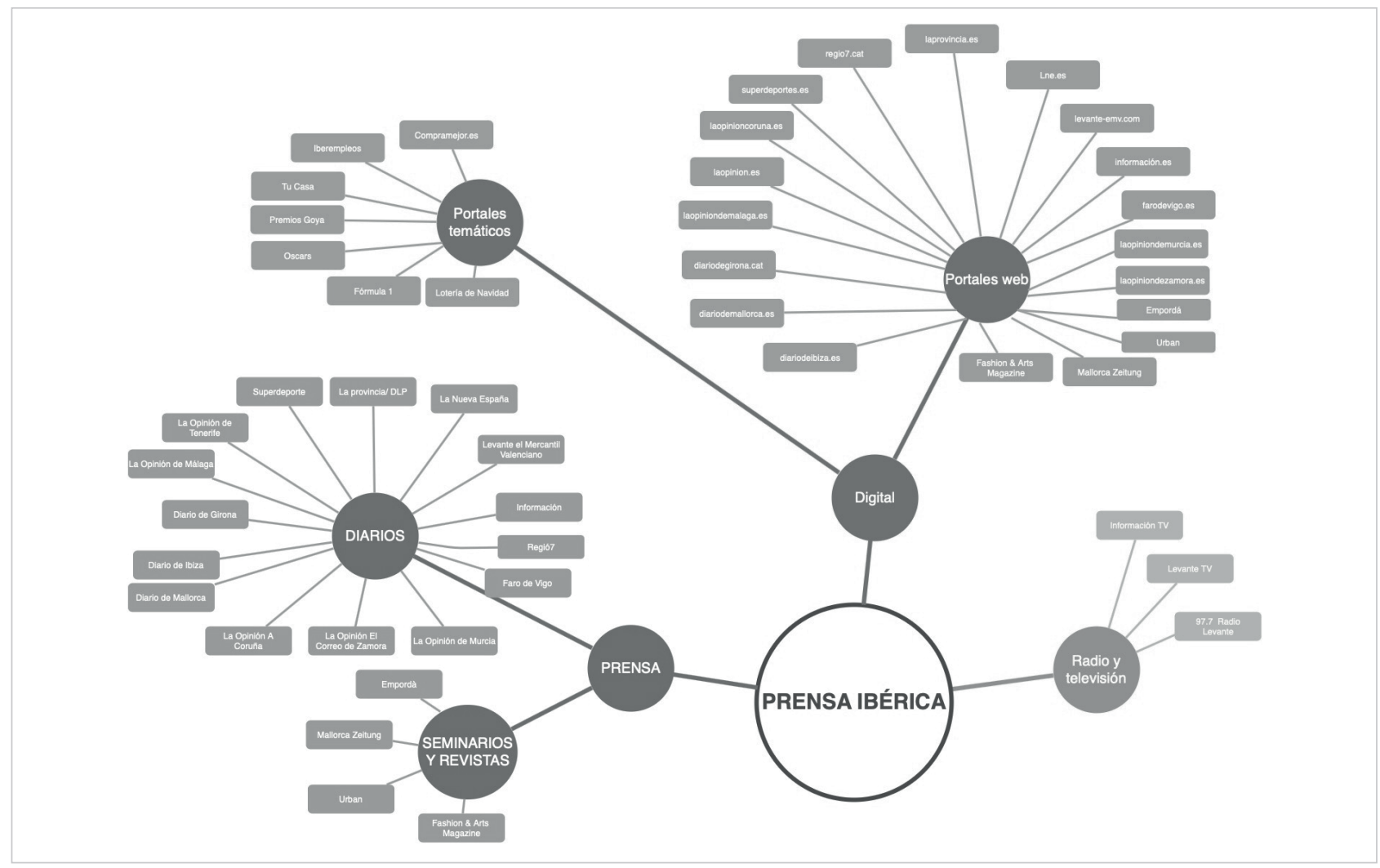

Imagen 11. Red de sitios web del Grupo Prensa Ibérica.

Fuente: elaborado con datos de la web oficial del Grupo Prensa Ibérica

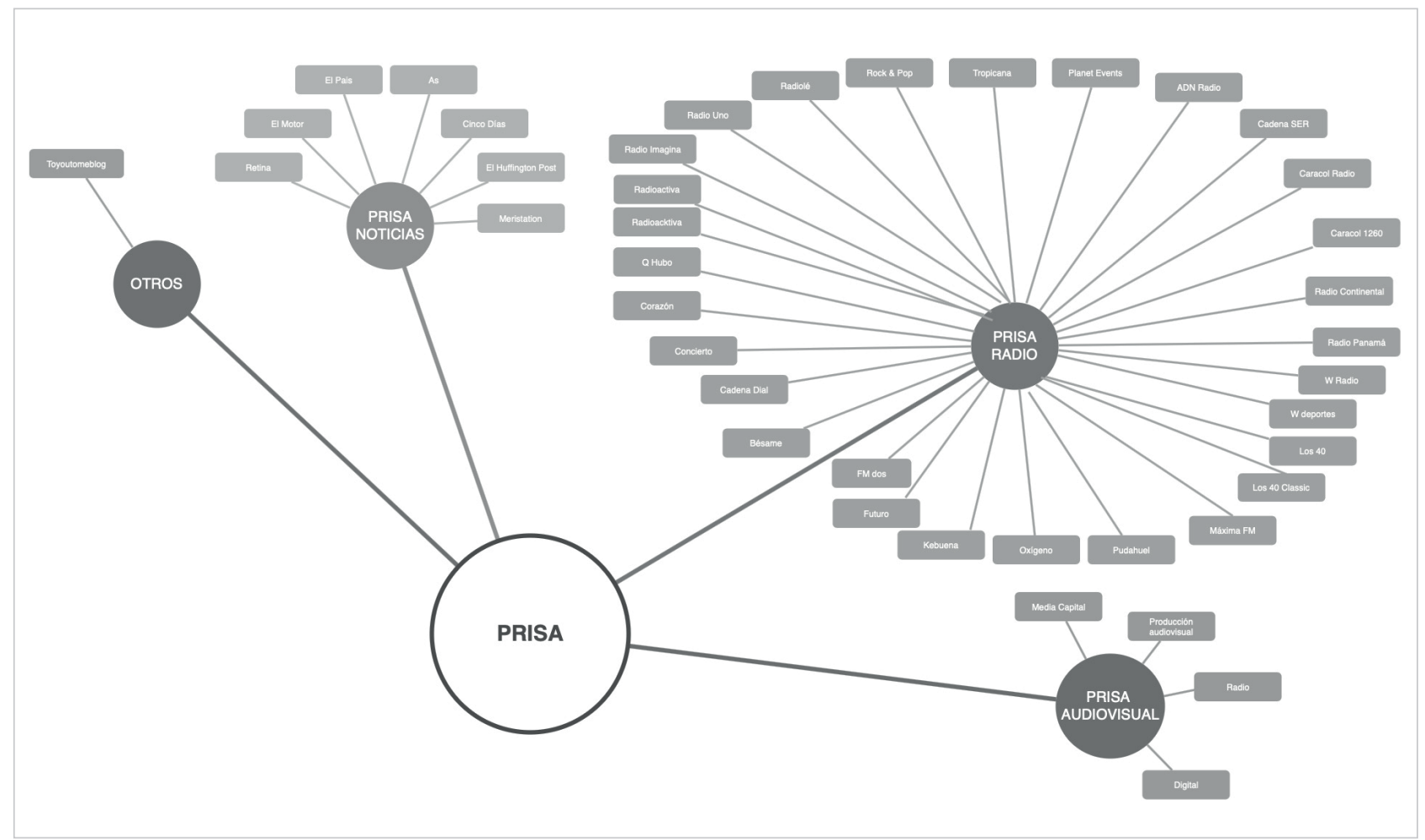

Imagen 12. Red de sitios web del Grupo Prisa.

Fuente: elaborado con datos de la web oficial del Grupo Prisa. 


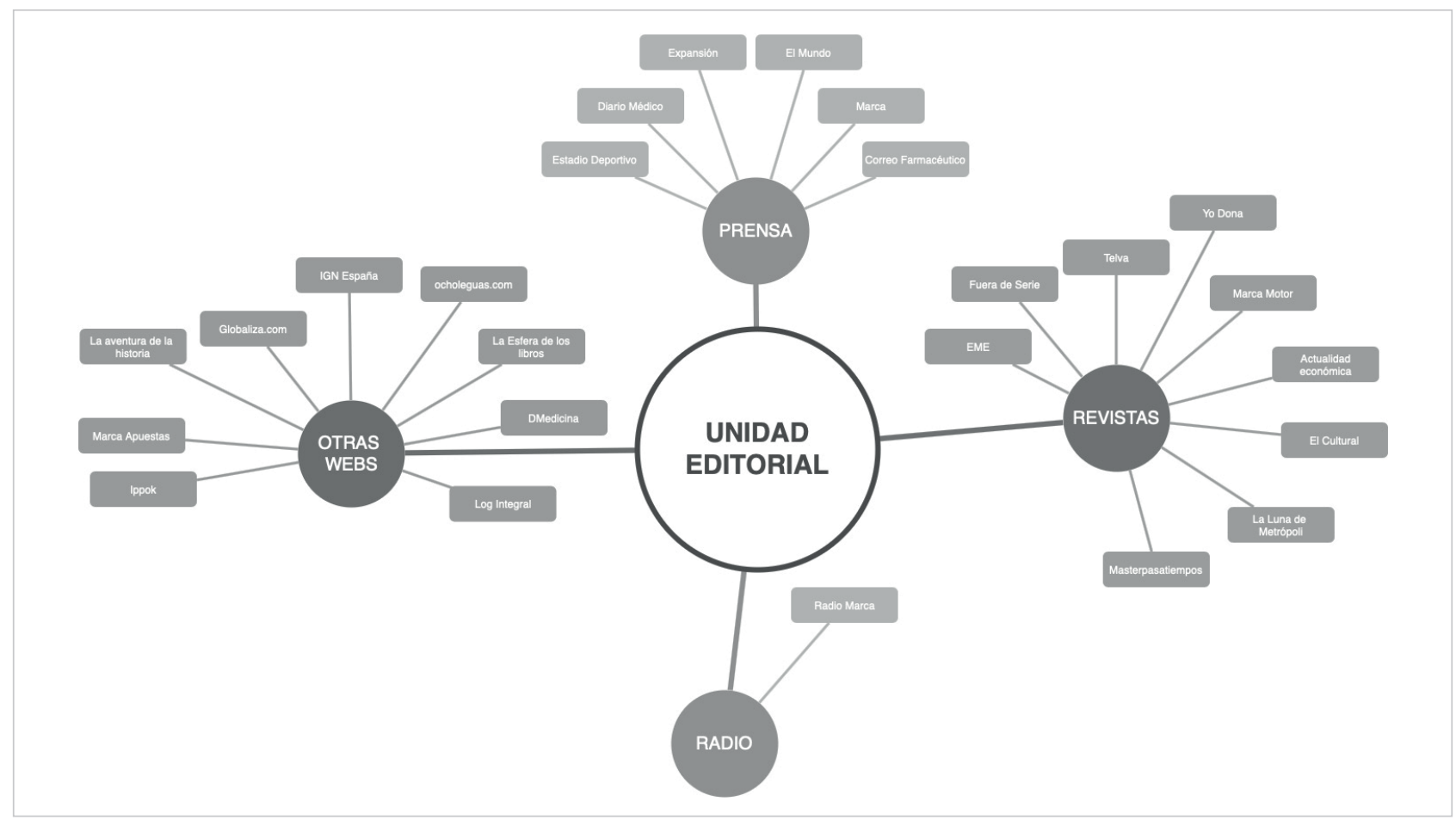

Imagen 13. Red de sitios web del Grupo Unidad Editorial.

Fuente: elaborado con datos de la web oficial del Grupo Unidad Editorial

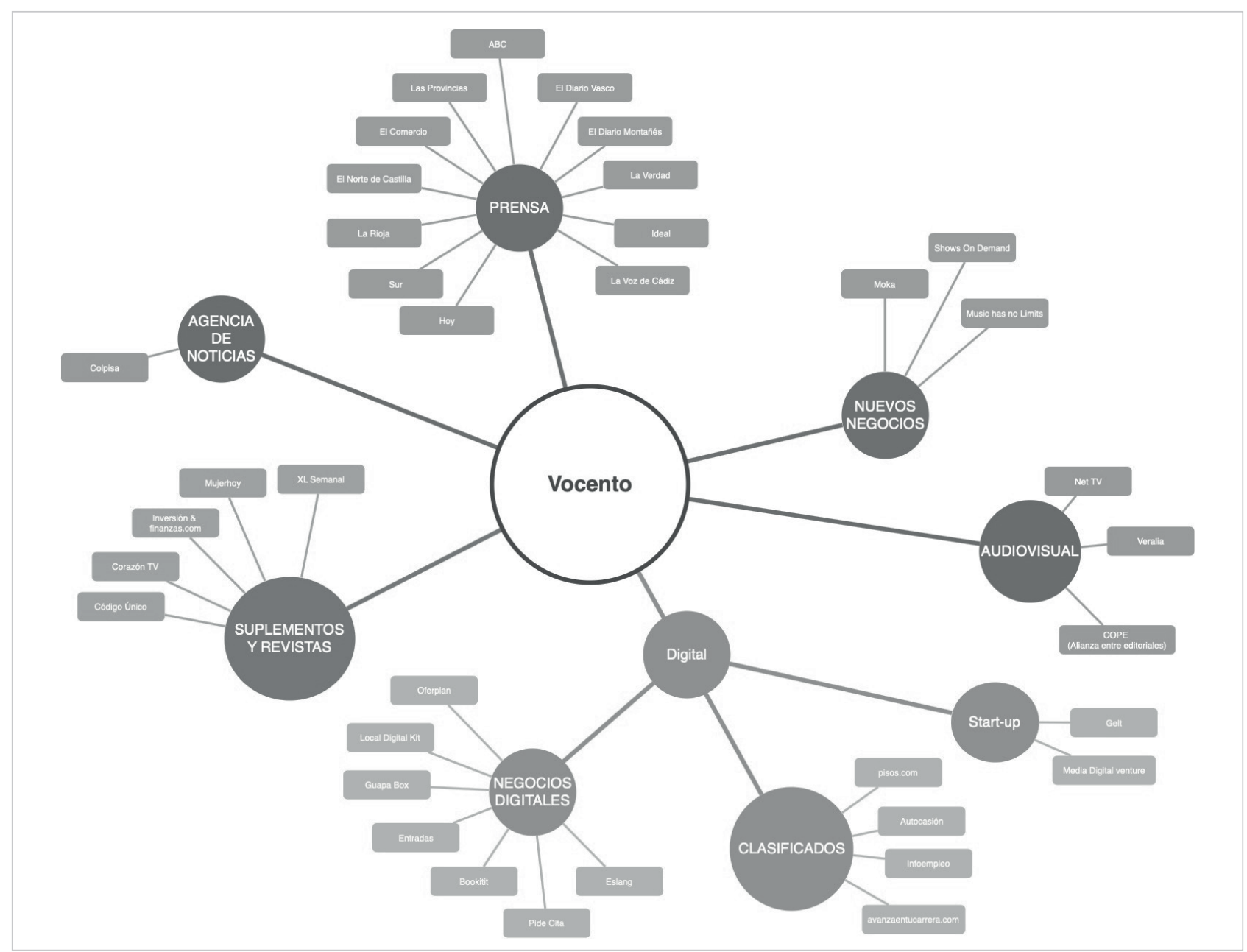

Imagen 14. Red de sitios web del Grupo Vocento.

Fuente: elaborado con datos de la web oficial del Grupo Vocento 


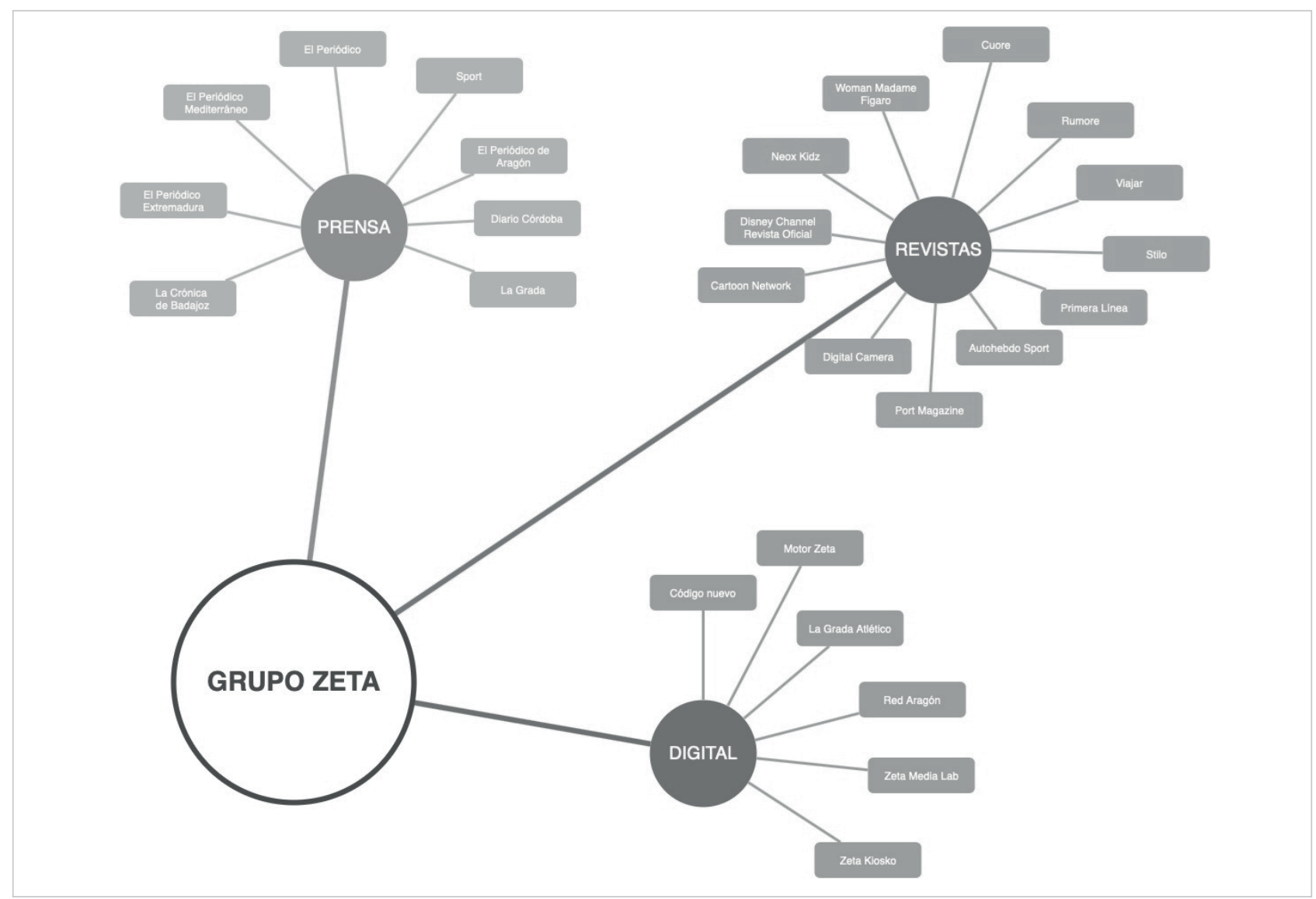

Imagen 15. Red de sitios web del Grupo Zeta.

Fuente: elaborado con datos de la web oficial del Grupo Zeta.

En la tabla 3 se muestran los resultados de síntesis en visibilidad y autoridad web de 14 de los 15 grupos analizados. Descartamos Imagina por tener una estructura especial que no permite cuantificar a nivel de medios el margen de visibilidad web que tienen, ya que su actividad empresarial se centra en servicios de producción audiovisual, y no en cibermedios, radios, televisiones, o webs temáticas. Esto nos permite definir el mapa de visibilidad de los grupos mediáticos analizados. Entendemos como mapa de visibilidad la presentación de la estructura de la red de un conjunto de sitios web (en este caso de los principales grupos de comunicación españoles), su distribución en los resultados de búsqueda y su sistema de enlaces y dominios.

Tabla 3. Síntesis de visibilidad y autoridad web de los grupos

\begin{tabular}{|c|c|c|c|c|}
\hline \multicolumn{5}{|c|}{ Síntesis de resultados de los grupos mediáticos } \\
\hline Datos totales & Tráfico por búsquedas & Enlaces de entrada & $\begin{array}{l}\text { Dominios } \\
\text { de referencia }\end{array}$ & $\begin{array}{c}\text { Palabras clave en top } \\
100\end{array}$ \\
\hline Grupo Prisa & 73.232 .777 & 463.419 .000 & 253.833 & 4.597.245 \\
\hline Grupo Vocento & 47.399 .825 & 172.014 .609 & 225.685 & 6.053 .870 \\
\hline Grupo Unidad Editorial & 75.845 .830 & 179.958 .700 & 250.392 & 3.751 .382 \\
\hline Grupo COPE & 1.634 .100 & 4.197 .000 & 13.974 & 209.004 \\
\hline Grupo Planeta & 13.979 .900 & 59.501 .400 & 76.746 & 1.633 .663 \\
\hline Grupo Atresmedia & 12.008 .500 & 62.123 .000 & 59.755 & 1.285 .606 \\
\hline Grupo Mediaset & 17.501 .200 & 14.717 .200 & 36.426 & 573.243 \\
\hline Grupo Godó & 28.210 .396 & 30.925 .402 & 70.665 & 2.076 .073 \\
\hline Grupo Zeta & 17.690 .088 & 72.539 .522 & 65.328 & 1.834 .341 \\
\hline Grupo Prensa ibérica & 14.704 .800 & 122.658 .100 & 85.215 & 2.744 .215 \\
\hline Grupo Intereconomía & 621.001 & 3.345 .337 & 9.645 & 131.350 \\
\hline Grupo Hearst & 9.768 .700 & 36.062 .000 & 203.430 & 1.211 .603 \\
\hline Grupo Joly & 2.321 .500 & 32.503 .000 & 27.673 & 667.721 \\
\hline Grupo Henneo & 14.976 .300 & 57.303 .000 & 97.300 & 2.249 .848 \\
\hline
\end{tabular}


En la tabla 3 se muestra la síntesis global de visibilidad y autoridad web de cada grupo mediático como resultado de analizar las webs que conforman cada grupo empresarial con SEMrush. El resultado es una suma de los valores del dominio central de todos los sitios web que conforman cada grupo.

A partir de la tabla de los resultados obtenidos por cada grupo empresarial, vamos a aplicar el Índice Agregado de Visibilidad (tabla 4). Incluye los indicadores anteriormente descritos (I1-I5), la puntuación total de la suma de los indicadores (T) y la puntación IAV de cada uno de los grupos mediáticos seleccionados.

Tabla 4. Resultados del análisis del Índice Agregado de Visibilidad

\begin{tabular}{|c|c|c|c|c|c|c|c|}
\hline \multicolumn{8}{|c|}{ Análisis de Índice Agregado de Visibilidad (IAV) } \\
\hline Grupo mediático & 11 & 12 & 13 & 14 & 15 & $\mathbf{T}$ & IAV \\
\hline Prisa & 14 & 13 & 14 & 14 & 13 & $68 / 70$ & 0,97 \\
\hline Vocento & 13 & 12 & 12 & 12 & 14 & $63 / 70$ & 0,90 \\
\hline Unidad Editorial & 9 & 14 & 13 & 13 & 12 & $61 / 70$ & 0,87 \\
\hline Prensa Ibérica & 12 & 7 & 11 & 9 & 11 & $50 / 70$ & 0,71 \\
\hline Zeta & 11 & 10 & 10 & 6 & 7 & $44 / 70$ & 0,62 \\
\hline Henneo & 4 & 8 & 7 & 10 & 10 & $39 / 70$ & 0,55 \\
\hline Planeta & 8 & 6 & 8 & 8 & 8 & $38 / 70$ & 0,54 \\
\hline Godó & 6 & 11 & 4 & 7 & 9 & $37 / 70$ & 0,52 \\
\hline Hearst & 10 & 4 & 6 & 11 & 5 & $36 / 70$ & 0,51 \\
\hline Atresmedia & 5 & 5 & 9 & 5 & 6 & $30 / 70$ & 0,42 \\
\hline Mediaset & 7 & 9 & 3 & 4 & 3 & $26 / 70$ & 0,37 \\
\hline Joly & 7 & 3 & 5 & 3 & 4 & $22 / 70$ & 0,31 \\
\hline COPE & 3 & 2 & 2 & 2 & 2 & $11 / 70$ & 0,15 \\
\hline Intereconomía & 3 & 1 & 1 & 1 & 1 & $7 / 70$ & 0,10 \\
\hline
\end{tabular}

A partir de la tabla de los resultados agregados obtenidos por cada grupo mediático (tabla 4), vamos a revisar la situación de cada uno de ellos. Gracias al IAV se puede hacer una estimación estratégica para cada uno de los grupos.

La tabla 5 muestra los resultados del análisis del IAV e incluye los aspectos destacados de cada grupo mediático y las dos estrategias identificadas para mejorar la puntuación en el IAV. La estrategia de mejora 1 consiste en posicionar un mayor número de palabras clave que tengan un volumen de búsqueda mensual elevado. La estrategia de mejora 2 debe conseguir más enlaces externos de más webs con autoridad alta.

Tabla 5. Aspectos destacados de los grupos y estrategias de mejora

\begin{tabular}{|c|c|c|c|}
\hline Grupo & Aspectos destacados IAV & $\begin{array}{c}\text { Estrategia de } \\
\text { mejora } 1\end{array}$ & $\begin{array}{l}\text { Estrategia de } \\
\text { mejora } 2\end{array}$ \\
\hline Prisa & $\begin{array}{l}\text { Es el grupo mediático que mejor índice IAV ha obtenido, obtiene la mejor pun- } \\
\text { tuación en el apartado de mayor número de webs por grupo y en el apartado } \\
\text { de transferencia de autoridad en base a enlaces referidos y webs enlazadas. }\end{array}$ & $x$ & \\
\hline Vocento & $\begin{array}{l}\text { Destaca por tener más palabras clave posicionadas entre los } 100 \text { primeros re- } \\
\text { sultados de búsqueda respecto al resto de grupos analizados. }\end{array}$ & & $x$ \\
\hline Unidad editorial & $\begin{array}{l}\text { Es el grupo con mayor tráfico por búsquedas, independientemente de que no } \\
\text { ocupe la primera posición en cuanto a número de palabras clave en las pri- } \\
\text { meras } 100 \text { posiciones, lo que significa que tiene posicionadas menos palabras } \\
\text { clave que otros grupos mediáticos, pero en cambio esas palabras tienen un } \\
\text { mayor volumen de búsqueda y por tanto son de mayor calidad. }\end{array}$ & & $x$ \\
\hline Prensa lbérica & $\begin{array}{l}\text { Es uno de los grandes grupos en cuanto a número de webs, pero en conjunto } \\
\text { no tienen un tráfico destacado frente a otros competidores. }\end{array}$ & $x$ & \\
\hline Zeta & $\begin{array}{l}\text { Está compuesto por un gran número de webs, con un tráfico de búsqueda } \\
\text { elevado y además recibe un gran número de enlaces externos que le permite } \\
\text { tener una gran autoridad web. Sin embargo, no tiene buenos resultados en } \\
\text { cuanto a dominios de referencia y a número de palabras clave posicionadas } \\
\text { entre los } 100 \text { primeros resultados de Google. }\end{array}$ & $x$ & $x$ \\
\hline Henneo & $\begin{array}{l}\text { Posee una gran solidez en su perfil de enlaces recibidos por dominios de re- } \\
\text { ferencia y por el número de palabras clave posicionadas en los } 100 \text { primeros } \\
\text { resultados de Google. }\end{array}$ & & $x$ \\
\hline Planeta & $\begin{array}{l}\text { Tiene unos resultados muy estables entre todos los indicadores analizados. De } \\
\text { hecho, está por encima de la media en cuanto a número de webs, enlaces ex- } \\
\text { ternos recibidos, dominios de referencia que le enlazan y número de palabras } \\
\text { clave. Sin embargo, su tráfico web está por debajo de la media. }\end{array}$ & $x$ & \\
\hline Godó & $\begin{array}{l}\text { Posee muy buen tráfico de búsqueda, sin embargo, es uno de los grupos con } \\
\text { menor número de enlaces externos obtenidos. }\end{array}$ & & $x$ \\
\hline
\end{tabular}




\begin{tabular}{|c|c|c|c|}
\hline Hearst & $\begin{array}{l}\text { Destaca sobre todo por el gran número de webs que engloban a este grupo } \\
\text { y por el número de webs de referencia que enlazan a Hearst. Sin embargo, no } \\
\text { cuenta con un buen tráfico de búsqueda principalmente porque no posee un } \\
\text { gran número de palabras clave posicionadas entre los } 100 \text { primeros resultados } \\
\text { de búsqueda. }\end{array}$ & $x$ & \\
\hline Atresmedia & $\begin{array}{l}\text { Cuenta con un gran número de enlaces externos apuntando a sus webs, sin } \\
\text { embargo, está por debajo de la media en los demás indicadores. }\end{array}$ & $x$ & \\
\hline Mediaset & $\begin{array}{l}\text { Se caracteriza principalmente por su tráfico orgánico que está por encima de } \\
\text { la media del ranking IAV. }\end{array}$ & $x$ & $\mathrm{x}$ \\
\hline Joly & $\begin{array}{l}\text { Destaca por estar compuesto por un gran número de sitios web, sin embargo } \\
\text { pueden mejorar el número de palabras clave posicionadas en los buscadores. }\end{array}$ & & $x$ \\
\hline COPE & $\begin{array}{l}\text { Tiene un índice IAV bajo ya que no destaca por sus buenos resultados de los } \\
\text { indicadores si tomamos como referencia al resto de grupos mediáticos anali- } \\
\text { zados. }\end{array}$ & $x$ & $\mathrm{X}$ \\
\hline Intereconomía & $\begin{array}{l}\text { Es el grupo que peor índice IAV ha obtenido, ya que ocupa la posición más } \\
\text { baja en tráfico orgánico, enlaces externos apuntando a sus webs, dominios de } \\
\text { referencia y palabras clave posicionadas entre las } 100 \text { palabras posiciones de } \\
\text { los motores de búsqueda. }\end{array}$ & $x$ & $\mathrm{X}$ \\
\hline
\end{tabular}

\section{Conclusiones}

A continuación examinaremos los objetivos y después presentaremos las conclusiones.

En primer lugar, es importante destacar que se han identificado los sitios web de cada uno de los grupos mediáticos estudiados y se ha analizado su estructura.

Asimismo, gracias a la identificación y descripción de dicha estructura se han podido reconocer los sitios web de los grupos que constituyen nuestros casos de estudio. Además, se ha podido comprobar el grado de visibilidad web y de autoridad de cada grupo en su conjunto. Y por último se ha podido crear un ranking de posicionamiento web de los principales grupos mediáticos a partir de su tráfico orgánico, palabras clave y enlaces obtenidos.

\section{Objetivo 1}

Se ha podido comprobar que todos los grupos mediáticos analizados diversifican sus productos; algunos tienen una mayor diversificación que otros, dependiendo de sus recursos y del tamaño del grupo. Todos ellos destacan por contar con productos en internet, como las versiones digitales de sus periódicos, radios o televisiones. Sin embargo, llama la atención que también cuentan con portales web verticales centrados en un tema concreto. Los temas que más se repiten son "empleo", "viajes" y "cocina".

- Prisa destaca por concentrar sus productos en radio y en prensa.

- Vocento cuenta con productos informativos en prensa, televisión, radio y webs verticales.

- Unidad Editorial estructura sus productos en prensa, revistas, radio y digital.

- COPE centraliza su unidad de negocio en la radio, con cadenas de referencia como COPE, Cadena 100 y RockFM.

- Planeta destaca principalmente por contar con el periódico La razón, tanto en su versión papel como en su versión digital. Cuenta además con participaciones en Atresmedia TV y Atresmedia Radio.

- Atresmedia y Mediaset cuentan con sus portales de vídeo bajo demanda (VoD) Atresplayer y Mitele, respectivamente, que permiten al usuario ver contenido interactivo de sus principales programas, tanto en streaming como en diferido.

- Godó posee productos en radio, prensa, televisión y cibermedios.

- Zeta destaca por publicar periódicos regionales y por contar con revistas temáticas.

- Prensa Ibérica se centra en productos informativos locales y especializados en televisión, radio, prensa y cibermedios.

- Intereconomía se caracteriza por concentrar sus productos en radio, televisión y prensa.

- Hearst posee dos líneas principales de negocio, una centrada en la difusión de noticias en abierto y la otra exclusiva para trabajadores y directivos de empresas específicas.

- Joly cuenta con cabeceras en papel y en digital regionales enfocadas a Andalucía.

- Henneo destaca por contar con una línea de negocio principal centrada en prensa, aunque también posee participación en radio y televisión.

\section{Objetivo 2}

Se deduce de nuestro análisis que todos los grupos mediáticos analizados cuentan con un tráfico orgánico, un número de palabras clave y un número de enlaces de webs de referencia muy alto si las comparamos con la gran mayoría de webs empresariales españolas ajenas a la liga de medios de comunicación. Esto permite confirmar que todos ellos tienen presente, en mayor o menor medida, que la visibilidad de sus sitios web es un valor añadido para poder atraer lectores.

Por lo tanto, es factible llevar a cabo un protocolo comparativo de la visibilidad de las redes de sitios web de los grupos mediáticos a través del uso de herramientas de auditoría SEO que permitan conocer el tráfico web orgánico, el número de palabras clave posicionadas entre las 100 primeras posiciones del buscador, a partir del número de enlaces externos (backlinks) obtenidos y el número de dominios de referencia que les enlazan. 


\section{Objetivo 3}

Se ha podido constatar que Unidad Editorial es el grupo con mayor tráfico de búsqueda orgánica, con 75.845 .830 puntos, mientras que Intereconomía, con 621.001 puntos, es el grupo que tiene menor visibilidad web y por tanto menor tráfico.

Prisa es el grupo con mayor número de dominios de referencia, es decir, mayor número de webs externas que envían enlaces a las webs de este grupo de comunicación, en total 253.833 dominios. Por el contrario, Intereconomía es el grupo con menor número de dominios de referencia, 9.645.

Vocento es el grupo con mayor número de palabras clave posicionadas entre las 100 primeras posiciones de Google, en concreto, 6.053.870 palabras. En el lado opuesto, nos encontramos nuevamente con Intereconomía, con 131.350 palabras entre los 100 primeros resultados de Google España.

En este mapa de visibilidad no se incluye Imagina, al contar con unas características específicas en su actividad empresarial diferente al resto de grupos analizados.

En definitiva, la visibilidad web y el posicionamiento en buscadores se está convirtiendo en una práctica esencial para los medios de comunicación, ya que una gran parte de la sociedad se informa a través de los motores de búsqueda y los resultados mejor posicionados en sus índices. Ante esto, los grupos mediáticos deben adaptarse y trabajar sus estrategias de posicionamiento web.

\section{Referencias}

Almiron, Núria (2009). "Grupos privados propietarios de medios de comunicación en España: principales datos estructurales y financieros". Comunicación y sociedad, v. 23, n. 1, pp. 243-273.

https://repositori.upf.edu/handle/10230/33689

Arias-Robles, Félix (2016). "Teoría y práctica del lenguaje ciberperiodístico. SEO, redes e (hiper)textos". Revista mediterránea de comunicación, v. 7, n. 2, pp. 177-194.

https://doi.org/10.14198/MEDCOM2016.7.2.8

Asser, Martin (2012). "Search engine optimisation in BBC News". BBC.

http://www.bbc.co.uk/blogs/bbcinternet/2012/09/search_engine_optimisationin.html

Charlton, Graham (2016) “How much do journalists and editors need to know about SEO?”. Search engine watch. https://searchenginewatch.com/2016/03/15/how-much-do-journalists-and-editors-need-to-know-about-seo

Codina, Lluís; Iglesias-García, Mar; Pedraza-Jiménez, Rafael; García-Carretero, Lucía (2016). Search engine optimization and online journalism: The SEO-WCP framework. Barcelona: Universidad Pompeu Fabra; Departamento de Comunicación. Serie Editorial DigiDoc.

https://doi.org/10.13140/RG.2.1.1337.6403

Coller, Xavier (2005). Estudio de casos. Madrid: Centro de Investigaciones Sociológicas. ISBN: 8474763878

Costa-Sánchez, Carmen; Guarinos-Galán, Virginia (2018). “Gestión de marca corporativa online de los canales públicos de televisión en Europa. Propuesta de indicadores para su medición”. Revista latina de comunicación social, n. 73, pp. 895-910.

https://doi.org/10.4185/RLCS-2018-1287

Dick, Murray (2011). "Search engine optimisation in UK news production". Journalism practice, v. 5, n. 4, pp. 462-477. https://doi.org/10.1080/17512786.2010.551020

Eisenhardt, Kathleen M. (1989). "Building theories from case study research". Academy of management review, v. 14, n. 4, pp. 532-550.

https://doi.org/10.5465/amr.1989.4308385

García-Carretero, Lucía; Codina, Lluís; Díaz-Noci, Javier; Iglesias-García, Mar (2016). “Herramientas e indicadores SEO: características y aplicación para análisis de cibermedios”. El profesional de la información, v. 25, n. 3, pp. 497-504. https://doi.org/10.3145/epi.2016.may.19

García-Orosa, Berta; López-García, Xosé (2015). “Los titulares en los principales cibermedios europeos: más funcionales y menos conceptuales". Estudios sobre el mensaje periodístico, v. 21, n. 2, pp. 833-847.

https://doi.org/10.5209/rev_ESMP.2015.v21.n2.50887

Giomelakis, Dimitrios; Veglis, Andreas (2015). "Employing search engine optimization techniques in online news articles". Studies in media and communication, v. 3, n. 1, pp. 22-33.

https://doi.org/10.11114/smc.v3i1.683

Giomelakis, Dimitrios; Veglis, Andreas (2016). “Investigating search engine optimization factors in media websites. The case of Greece". Digital journalism, v. 4, n. 3, pp. 379-400.

https://doi.org/10.1080/21670811.2015.1046992 
Gonzalo-Penela, Carlos (2015). Posicionamiento web y dinámicas de información en motores de búsqueda: propuestas de análisis y estudio comparativo de visibilidad de contenidos digitales en el caso de procesos electorales. Tesis doctoral. Barcelona: Universitat Pompeu Fabra.

https://www.tdx.cat/handle/10803/292730

Google (2019). "Search quality rating guidelines". Google.

https://static.googleusercontent.com/media/guidelines.raterhub.com/en//searchqualityevaluatorguidelines.pdf

Humprecht, Edda; Esser, Frank (2018). "Mapping digital journalism: Comparing 48 news websites form six countries". Journalism, v. 19, n. 4, pp. 500-518.

https://doi.org/10.1177/1464884916667872

Iglesias-García, Mar; Codina, Lluís (2016) “Los cibermedios y la importancia estratégica del posicionamiento en buscadores (SEO)". Opción, v. 32, n. 9, pp. 929-944.

https://www.redalyc.org/pdf/310/31048482052.pdf

Labio-Bernal, Aurora; Nogales-Bocio, Antonia-Isabel (2010). "Poder medios de comunicación, y periodismo". En: Reig, Ramón (coord.). La dinámica periodística: perspectiva, contexto, métodos y técnicas. Sevilla: Asociación Universitaria Comunicación y Cultura. ISBN: 9788493760007

https://idus.us.es/handle/11441/30648

López-García, Guillermo (2015). Periodismo digital: redes, audiencias y modelos de negocio. Madrid: Comunicación Social. Ediciones y Publicaciones. ISBN: 9788415544937

López-García, Guillermo (2017). “Comunicación política y discursos sobre el poder". El profesional de la información, v. 26, n. 4, pp. 573-578.

https://doi.org/10.3145/epi.2017.jul.01

Lopezosa, Carlos; Codina, Lluís; Pérez-Montoro, Mario (2019). "SEO and digital news media: Visibility of cultural information in Spain's leading newspapers". Trípodos, n. 44, pp. 41-61.

http://www.tripodos.com/index.php/Facultat_Comunicacio_Blanquerna/article/view/618

Lopezosa, Carlos; Codina, Lluís; Rovira, Cristòfol (2019). Visibilidad web de portales de televisión y radio en España: ¿qué medios llevan a cabo un mejor posicionamiento en buscadores? Serie DigiDoc-EPI, n. 4. Barcelona: Universitat Pompeu Fabra, Departamento de Comunicación; Ediciones Profesionales de la Información SL. ISBN: 9788409077168 https://repositori.upf.edu/handle/10230/36234?locale-attribute=es

Noam, Eli (2017). "Beyond the mogul: From media conglomerates to portfolio media”. Journalism, v. 19, n. 8, pp. 10961130.

https://doi.org/10.1177/1464884917725941

Patel, Neil (2019). "Cómo publicar tu sitio en Google News y generar más tráfico en tiempo real”. Neilpatel.com. https://neilpatel.com/es/blog/como-publicar-tu-sitio-en-google-news-y-generar-mas-trafico-en-tiempo-real

Reig, Ramón (2011). Los dueños del periodismo: claves de la estructura mediática mundial y de España. Barcelona, Editorial Gedisa. ISBN: 9788497846189

Rodríguez-Fernández, María-Magdalena; Sánchez-Amboage, Eva; Toural-Bran, Carlos (2018). "Las radiotelevisiones públicas europeas en el entorno web". Revista latina de comunicación social, v. 73, pp. 911-926. https://doi.org/10.4185/RLCS-2018-1288

Smyrnaios, Nikos (2015). "Google and the algorithmic infomediation of news". Media fields journal, n. 10, pp. 1-10. http://static1.1.sqspcdn.com/static/f/707453/26682448/1447830671177/Smyrnaios_FINAL.pdf

Smyrnaios, Nikos; Rebillard, Frank (2009). "L'actualité selon Google. L'emprise du principal moteur de recherche sur I'information en ligne". Communication et langages, n. 160, pp. 95-109.

https://doi.org/10.4074/S0336150009002087

Smyrnaios, Nikos; Sire, Guillaume (2014). "The news according to Google: How does algorithmic infomediation frame the work of French journalists?". In: JSS-Ecrea 2014 Conference, Thessaloniki, March 27-29.

https://es.slideshare.net/smyrnaios/the-news-according-to-google-how-does-algorithmic-infomediation-frame-thework-of-french-journalists

Wilson, Lee (2016). "How to get your website listed in Google News". Search engine journal, March 30. https://www.searchenginejournal.com/how-to-get-your-website-listed-in-google-news-in-2016/159701

Wordtracker (2018). "A guide to SEO for editorial teams and journalists". Wordtracker.

https://www.wordtracker.com/academy/seo/getting-started/seo-for-editorial-teams-journalists

Yin, Rober K. (2014). Case study research. Design and methods. Canadá: SAGE. ISBN: 9781452242569 